\title{
A Conceptual Model for Production Leveling (Heijunka) Implementation in Batch Production Systems
}

\author{
Luciano Fonseca de Araujo and Abelardo Alves de Queiroz \\ Federal University of Santa Catarina, Department of Manufacturing, \\ GETEQ Research Group, Caixa Postal 476, Campus Universitário, Trindade, \\ 88040-900, Florianópolis, SC, Brazil \\ Ifaraujo2005@gmail.com, abelardo@emc.ufsc.br
}

\begin{abstract}
This paper explains an implementation model for a new method for Production Leveling designed for batch production system. The main structure of this model is grounded on three constructs: traditional framework for Operations Planning, Lean Manufacturing concepts for Production Leveling and case study guidelines. By combining the first and second construct, a framework for Production Leveling has been developed for batch production systems. Then, case study guidelines were applied to define an appropriate implementation sequence that includes prioritizing criteria of products and level production plan for capacity analysis. This conceptual model was applied on a Brazilian subsidiary of a multinational company. Furthermore, results evidence performance improvement and hence were approved by both managers and Production personnel. Finally, based on research limitations, researchers and practitioners can confirm the general applicability of this method by applying it in companies that share similarities in terms of batch processing operations.
\end{abstract}

Keywords: Batch Production, Heijunka, Implementation Model, Production Leveling.

\section{Introduction}

Due intense competition, both traditional and emerging companies must improve existing methods for Operations Planning (OP). Indeed, Production Leveling improves operational efficiency in five objectives related to flexibility, speed, cost, quality and customers' service level [1], [6], [10].

Production Leveling combines two well known concepts of Lean Manufacturing: Kanban System and Heijunka. The former means pull signaling of production based on concept for supermarket replenishment to control work-in-process inventory. The latter means a smother pattern for daily production sequencing at assembling lines [8], [9], [10].

Even though such concepts are relevant on literature, one can argue about whether or not Lean Manufacturing concepts can be generally applicable [5]. Hence, three 
main gaps of literature review can also be used to support such statement. First of all, both conceptual models and problem solving [2] are focused on mixed model assembling lines. Secondly, it can be said that batch production is suitable to a wide variety of manufacturing processes, even in automotive supply chains [3]. Finally, regarding that Production Leveling is often described as simple models and concepts [9], [10], the control of batch processes is often referred by using a triangle Kanban for few product models [8], [10]. Indeed, this implies that batch production always comprises a minor part of a value stream. Based on those statements, one question arises above all others. The question is: What are the steps necessary to level out the production when batch processes represent a major part of a value stream? Thus, there was no method based on Production Leveling designed for batch production processes and its variations related to many industrial applications [1].

Based on those gaps found on literature, this paper aims to present an implementation model for Production Leveling designed for batch production systems. Additionally, this conceptual model was applied in a major qualitative research in early 2008 in a large multinational company, located on state of São Paulo, Brazil [1]. Thus, this paper is organized as follows. In section 2, a literature review of the main concepts is presented, including the structure of Production Leveling well its main activities. In section 3, research methodology is briefly explained. Section 4 presents an implementation model. This paper ends with conclusions in section 5. Furthermore, author state that this method is suitable with all manufacturing systems that share similarities within its processing operations [1]. Hence, this general applicability is briefly summarized by providing a classification of batch processing operations in Appendix A.

\section{Literature Review}

This section briefly presents the theoretical framework of the new method [1] which main structure was developed based on a previous literature review. This study was designed by combining the traditional framework for Operations Planning (OP) [9], [12] for make-to-stock positioning strategy and basic concepts of Lean Manufacturing [8], [10], [13].

\subsection{Theoretical Framework for Production Leveling}

The traditional approach for OP comprises three levels of decisions related to a planning horizon ahead of time: Strategic (long term), Tactical (medium term) and Operational (short term). Regarding that Lean Manufacturing practices differ from classical approach for OP in both Tactical and Operational Level [12], this method has developed by replacing classical activities of OP by Lean Manufacturing ones in such levels [1] as depicted in Fig. 1 as follows: 


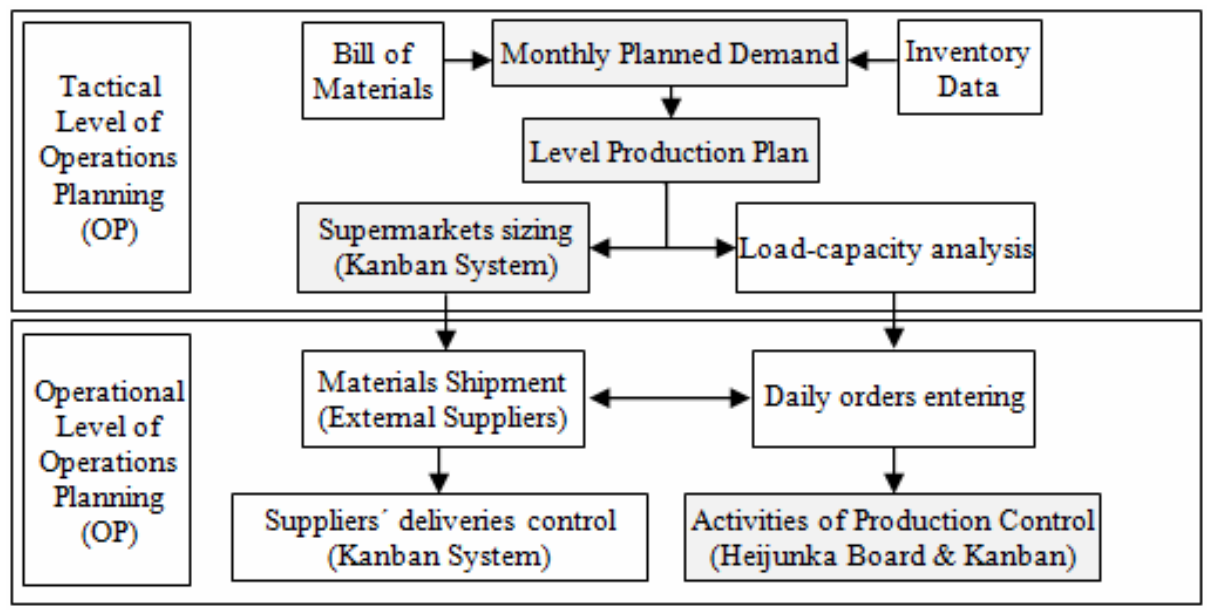

Fig. 1. Theoretical framework of Production Leveling and its main activities

Those activities highlighted at light gray boxes are shortly described as follows.

\subsubsection{Tactical Level}

The Monthly Planned Demand includes a decision based on inventory data, bill of materials and customers' orders data. Hence, materials planners must define a planned volume (demand) for every product model for the following month. One of the key features of Production Leveling comprises the prioritization of product models due product variety. It usually suggests a make-to-stock production for both high and medium volume (' $\mathrm{A}$ ' and ' $\mathrm{B}$ ' items) whereas a make-to-order production for low volume (' $\mathrm{C}$ ' items) [10]. Based on that decision, a Level Production Plan must be developed to generate a leveled production pattern [7]. It features information about production models, production batch size, set up time and a planning time horizon that can be fixed as six or more days [1], [7]. The 'required capacity', named as production pitch or pitch, is also calculated for every product model and comprises a total elapsed time necessary to produce an entire single batch for one given product model. Thus, it comprises an analysis of both required and available capacity of process. Finally, Supermarket sizing is a materials planning activity to quantify inventory storage points using the Kanban System.

\subsubsection{Operational Level}

Activities of Production Control feature shop-floor routines such as loading, sequencing, scheduling, dispatching and control. In a Lean Manufacturing environment, visual controls provide useful information about normal condition. These tools includes Kanban Board or Electronic Kanban as well Heijunka Board and Production Rate Control Board [1] for daily control of production completion.

\section{Research Methodology}

Based on objectives of this paper, the implementation model was grounded on guidelines for case studies [4]. Hence it was divided into two phases. The first one, named 
Previous State, comprises the scenario before implementation of the proposed method. Secondly, Future State means the condition after this implementation. Those activities are presented in the following section.

\section{Implementation Model}

A case study can be applied to either single or multiple cases [4]. Indeed, it is worth highlighting that this implementation model is expected to be suitable to both single and multiple cases. In this paper, researched company should be generically named Company 'A'. The two phases, named Previous State and Future State, are also presented as follows.

\subsection{Previous State Analysis}

The analysis must include one industrial facility at a time on which studied value chain must be shortly described in terms of manufacturing processes and materials flow layout. Fig. 2 depicts the main activities of Previous State analysis:

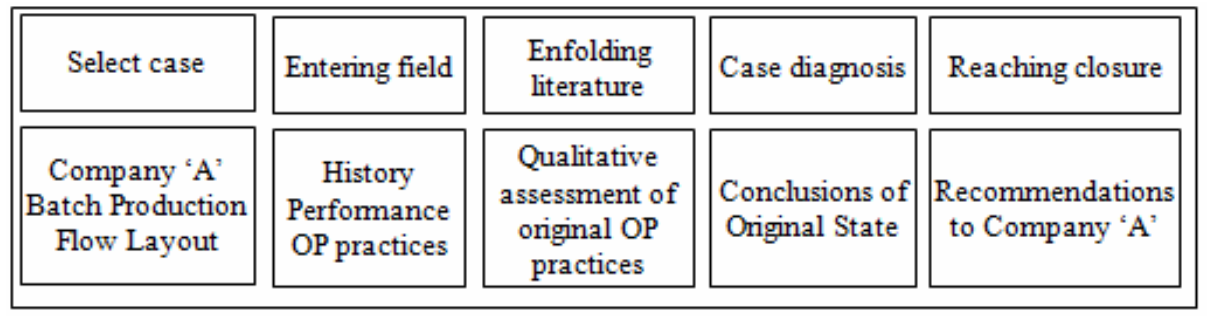

Fig. 2. First phase of the proposed methodology for Previous State analysis

If company and its processes features evidence that proposed method is suitable to Previous State scenario, then data must be collected in field including company history as well value stream performance and existing OP practices. After doing that, a qualitative assessment of such practices must be performed by comparing them with theoretical elements that composes Production Leveling. This activity comprises both principles and policies grounded on both Heijunka and Kanban Systems objectives and key features [1]. Hence, due paper limitation, a case study of this qualitative evaluation is going to be presented in details on a future research paper. After that assessment, researcher must conclude about Previous State and recommendations must be listed aiming to reach closure on the first phase.

\subsection{Future State Analysis}

Based on proposed approach [1], the second phase model begins with a training seminar, and a Pilot Project Planning structured on a PDCA cycle followed by a Pilot Project Execution. After that, performance indicators must be gathered and analyzed before and after the implementation. Furthermore, researcher must assess whether or 
not implemented practices adhere to Production Leveling principles and policies [1]. If so, based on facts and data, proposed method will be validated regarding research limitations. After that, the case study ends with conclusions and final recommendations. Those decisions are summarized in Fig. 3 as follows.

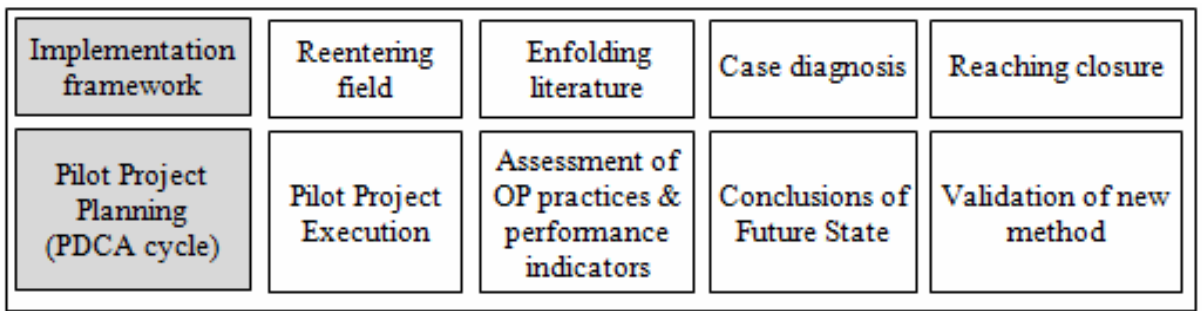

Fig. 3. Second phase of the proposed methodology for Future State analysis

\subsubsection{Implementation Framework}

Based on proposed model [1], the implementation framework highlighted on light gray box in Fig. 3 includes a Pilot Project Planning that starts with a Level Production Plan. Hence, such activity is described in Fig. 4 as follows:

\begin{tabular}{|c|c|}
\hline Prionitize 'A' and 'B' items & Select high and medium volume items \\
\hline Select the interval & Select the planning time interval \\
\hline Calculate production cycle and batch size & Set number of set up and production batches \\
\hline Calculate required capacity for each batch & Calculate 'production pitch' or 'pitch' \\
\hline Distribute batches within interval & Allocate both batches and its pitches \\
\hline Level the mix and required capacity & Optimize the leveled production pattem \\
\hline
\end{tabular}

Fig. 4. Activities of the Level Production Plan designing

Fig. 4 shows the proposed method that includes the criterion for classification of products based on monthly demand, namely $A B C$ analysis. After selecting prioritized items, researcher must to design a Level Production Plan for each machine that comprises the studied value stream. This plan can be alternatively designed by leveling the required capacity using the following information [1]: Set up or Changeover time, production batch size and production rate at the studied machine. Additionally, process stability and its related constraints must be listed for further analysis. The first decision is a calculation of production cycle within interval related to the theoretical number of monthly set up operations. Second decision comprises the required capacity (production pitch or pitch) for each product model related total processing time elapsed from setting up machine till processing an entire production batch. Finally, this plan comprises visual information as depicted on Fig. 5 [1]. 


\begin{tabular}{|c|c|c|c|c|c|c|c|c|c|c|}
\hline Product Model & 1 & Pitch & 2 & Pitch & 3 & Pitch & 4 & Pitch & 5 & Pitch \\
\hline A & 250 & 213 & 250 & 213 & 250 & 213 & 250 & 213 & 250 & 213 \\
\hline B & 220 & 190 & 220 & 190 & 220 & 190 & 220 & 190 & 220 & 190 \\
\hline C & 210 & 183 & 210 & 183 & 210 & 183 & 210 & 183 & 210 & 183 \\
\hline D & 256 & 217 & & & 256 & 217 & & & 256 & 217 \\
\hline E & & & 250 & 213 & & & 250 & 213 & & \\
\hline F & 150 & 138 & & & 150 & 138 & & & 150 & 138 \\
\hline G & & & 240 & 205 & & & & & & \\
\hline H & & & & & & & 180 & 160 & & \\
\hline I & 180 & 160 & & & & & & & 180 & 160 \\
\hline J & & & & & 140 & 130 & & & & \\
\hline Daily Required Capacity (min) & & 1,168 & & 1,143 & & 1,168 & & 1,143 & & 1,168 \\
\hline Total Available Time (min) & & 1,214 & & 1,214 & & 1,214 & & 1,214 & & 1,214 \\
\hline Daily Remaining Time (min) & & 46 & & 71 & & 46 & & 71 & & 46 \\
\hline Utilization of Capacity (\%) & & $96 \%$ & & $94 \%$ & & $96 \%$ & & $94 \%$ & & $96 \%$ \\
\hline
\end{tabular}

Fig. 5. A Level Production Plan for one single machine featuring five days planning interval

Fig. 5 depicts a Level Production Plan with five days of planning interval. First left column has selected product models in machine whereas every day has production batches (columns labeled as numbers) and its related required capacity in minutes (columns labeled as 'Pitch'). After ending this activity, the next one comprises Kanban System designing regarding value stream features such as product variety, standard packages for product model, as depicted in Fig. 6.

\begin{tabular}{|c|c|}
\hline Define Pull System trigger & Choose the type of pull signaling \\
\hline Calculate Kanban Board cards & Calculate inventory amount \\
\hline Define operational rules & Define Kanban operational rules \\
\hline Define prionities criteria & Define dispatching priorities \\
\hline Define sequencing criteria & Define best daily production sequence \\
\hline Define information system & Define a data system for electronic Kanban \\
\hline Define a data collection routine & Define how to update daily inventory data \\
\hline
\end{tabular}

Fig. 6. Information flow applied to design a Kanban System

Finally, operational rules must be set to define how Production personnel must execute daily level scheduling and its five activities of production control by using visual controls such as Kanban Board and set of cards, Heijunka Board and Hourly Production Rate control. In some cases, due product variety, an electronic Kanban could be best suitable to control a Pull System. Finally, operational rules and its information flow are both depicted in Fig. 7. 


\begin{tabular}{|c|c|}
\hline Operate Pull System & Read daily inventory level \\
\hline Confirm replenishment signal & Verify electronic Kanbanindication \\
\hline Set batch size & Confirm production batch size \\
\hline Confirm daily load & Set daily load based on Kanban indication \\
\hline Sequence production batches & Set daily production sequence \\
\hline Load Heijunka Board & Put cards on the Heijunka Board \\
\hline Dispatch orders with production Kanban & Run daily scheduled production \\
\hline Control production rate & Control actual production completion \\
\hline
\end{tabular}

Fig. 7. Operational rules for Activities of Production Control

\section{Conclusions}

This paper presented an implementation model grounded on Production Leveling designed to batch production. The methodological approach was designed by using a guideline for case study and comprises an Previous State and Future State. Both phases include an analysis of OP practices. The major contribution of this paper is to present a new and simple method Production Leveling that was empirically tested in early 2008 that helped to achieve satisfactory results. This method is grounded on Lean Manufacturing concepts with major changes at Tactical and Operational levels. By defining an alternate method for Level Production Plan, future papers will show results of an implementation and qualitative assessment of proposed method. To conclude, based on research limitations, researchers and practitioners can apply these concepts aiming to test its general applicability in different scenarios of batch production with product variety in make-to-stock positioning strategy.

\section{Acknowledgements}

We would like to thank Conselho Nacional de Desenvolvimento Científico e Tecnológico $(\mathrm{CNPq})$ of Brazil for financial support. We would also like to thank the company where this research has been developed.

\section{References}

1. Araujo, L.F.: Method for application of Production Leveling in repetitive manufacturing systems with batch production (Master of Science Dissertation). Federal University of Santa Catarina. Department of Mechanical Engineering, p. 169 (2008) (in Portuguese)

2. Kotani, S., Ito, T., Ohno, K.: Sequencing Problem for a Mixed-Model Assembly Line In The Toyota Production System. Int. J. Prod. Res. 42(23), 4955-4974 (2004) 
3. Cooney, R.: Is Lean a Universal Production System? Batch Production in the Automotive Industry. Int. J. Op. \& Prod. Man. 22(10), 1130-1147 (2002)

4. Eisenhardt, K.: Building Theories from Case Study Research. The Academy of Management Review 14(4), 532-550 (1989)

5. Godinho Filho, M., Fernandes, F.C.F.: Lean Manufacturing: a literature review which classifies and analyses papers indicating new research. Gestão \& Produção 11(1), 1-19 (2004) (in Portuguese)

6. Jones, D., Womack, J., Roos, D.: The machine that has changed the world. Rio de Janeiro, Campus (2004) (in Portuguese)

7. Liker, J., Meier, D.: Toyota Way field book: a practical guide for implementing Toyotás 4Ps. McGraw-Hill, New York (2007)

8. Monden, Y.: Toyota Production System: An Integrated Approach, 3rd edn. Engineering \& Management Press, New York (1998)

9. Slack, N., Chambers, S., Johnston, R.: Operations Management, 2nd edn., Atlas (2002) (in Portuguese)

10. Smalley, A.: Creating Level Pull. Lean Enterprise Institute, São Paulo (2004) (in Portuguese)

11. Lee, H.L., Padmanabhan, V., Whang, S.: The bullwhip effect in supply chains. Sloan Management Review 38(3), 93-102 (1997)

12. Vollmann, T.E., Jacobs, F.R., Berry, W., Whybark, D.C.: Manufacturing planning and control systems for supply chain management, 5th edn. McGraw-Hill, New York (2006) (in Portuguese)

13. Shingo, S.: Toyota Production System: from the point of view of Production Engineering, Porto Alegre, Bookman (1996) (in Portuguese)

\section{Appendix A: Classification of Batch Processing Operations}

Proposed method can be generally applicable in batch process system whenever it shares the same kind of processing operations described as follows:

- Disjunctive type I - It converts a single piece of material into several parts, such as press stamping like processes by cutting up hot rolled steel coils to generate multiple purpose parts by varying materials, geometry and so forth.

- Disjunctive type II - It comprises some types of metallurgical processes that convert powder and pellets into a batch of parts such as extrusion and plastic injection molding. 